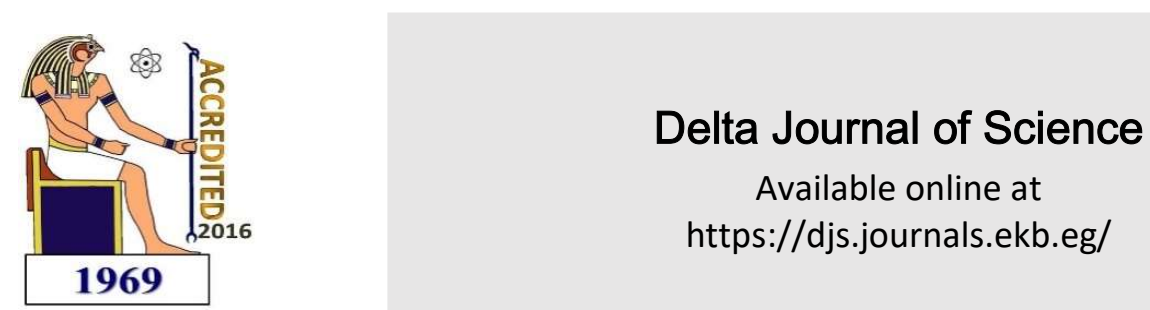

Research Article

BOTANY

\title{
Effect of different culture media on the growth and lipids of the green microalgae, Scenedesmus obliquus and Micractinium reisseri as a feedstock for biodiesel production
}

\author{
Abd El-Fatah I. Abomohra(1), Atef M. Abo-Shady(1), Ahmed M. Abd El-Moneim ${ }^{(2)}$, Hanan M. \\ Khairy $^{(2)}$, Rasha S. Marey ${ }^{(2)}$ \\ (1) Department of Botany. Faculty of Science, Tanta University, Tanta, Egypt \\ (2) National Institute of Oceanography and Fisheries, Alexandria, Egypt
}

\begin{abstract}
The aim of this study was to investigate the growth, lipid content and lipid productivity of the biodiesel promising microalgae Scenedesmus obliquus and Micractinium reisseri grown in batch culture using four different freshwater growth media, namely Chu-10, KC, Flory and Kuhl's medium to identify the most suitable medium for high lipid production for each species. The Results confirmed that Kuhl and KC showed the highest biomass productivity for $S$. obliquus and M. reisseri ( 0.05 and $0.07 \mathrm{~g} \mathrm{~L}^{-1} \mathrm{~d}^{-1}$, respectively). The Lipid content and lipid productivity were estimated at four different growth phases (early, middle, late exponential and stationary phase). The results revealed that, $M$. reisseri showed the highest lipid productivity at stationary phase $\left(17.08 \mathrm{mg} \mathrm{L}^{-1} \mathrm{~d}^{-1}\right)$, while $S$. obliquus showed lipid productivity of $12.61 \mathrm{mg} \mathrm{L}^{-1} \mathrm{~d}^{-1}$ which was insignificant with that at the late exponential phase $\left(12.55 \mathrm{mg} \mathrm{L}^{-1} \mathrm{~d}^{-1}\right)$. The fatty acids profile of $S$. obliquus and M. reisseri at stationary growth phase showed that both of them were suitable as feedstock for biodiesel production because of their high saturated fatty acids content that represented by $81.34 \%$ and $72.51 \%$ of the total fatty content, respectively. Palmitic acid (C16:0) was represented by 15.74 and $16.06 \%$ in the two studied species, respectively that increase the biodiesel quality for each strain. This study suggests $M$. reisseri cultivated on $\mathrm{KC}$ medium to provide high lipid productivity which offers a promise to be one of the sources of biodiesel.
\end{abstract}

Keywords: microalgae, Lipid productivity, growth media, Scenedesmus obliquus, Micractinium reisseri

\section{Introduction:}

In recent decades, the world has been faced an energy crisis, associated with irreversible depletion of traditional sources of fossil fuels which contribute to about $80 \%$ of global energy demand at present. However, their use as major form of energy is indeed unsustainable, further the accumulation of greenhouse gases in the atmosphere brings about global warming and causes global climate change, environmental pollution, and health problems (Singh and Gu, 2010; Chen et al., 2011). Therefore, there is a rapid need for development of new, clean, and sustainable energy sources. Among the various potential
Sources of renewable energy, biofuels are of most interest, and expected to play a crucial role in the global energy infrastructure in the future (Chisti, 2007; Lo et al., 2010). Biofuels (bioethanol and biodiesel) are currently receiving much attention due to it is made from nontoxic, biodegradable and renewable resources. This also provides environmental benefits, which gives rise to decrease in harmful emissions of carbon monoxide, hydrocarbons and decrease in greenhouse effect (Campbell et al., 2011). The use of biofuels can also play an important role in avoiding the excessive dependence on fossil fuels due to high cost of petroleum and to 
improve the environmental sustainability (Gouveia and Oliverira, 2009). Mostly biodiesel is currently produced from animal fats, waste cooking oils and vegetable oils (Barnwal and Sharma, 2005). Use of agriculture crops, especially edible oil crops such as corn, as a feedstock for biofuel has raised concerns of food security due to the competition with arable lands that is pushing the price of edible oil to unaffordable levels (Batten and O'Connell, 2007; Mata et al., 2010).

Therefore, Microalgae were discussed to be the promising source for biodiesel due to their simple cellular structure, higher growth rate and higher lipid content than terrestrial plants, since most of microalgae can complete an entire growing cycle every few days, which results in higher oil productivity than other oil crops (Stephens et al., 2010). The yield of oil from algae is over 200 times the yield of soybean oils (Gouveia and Oliverira, 2009). Moreover, microalgae can also be grown on non-arable lands (e.g. desert, seashore, rocky and sandy lands) which do not compete with food crops and can use saline water.

Biodiesel is produced by transesterification of oils through the reaction of triacylglycerides (TAGs) with simple alcohols leading to formation of a chemical compound known as fatty acid methyl esters (FAMEs), which is known more generically as biodiesel (Fukuda et al., 2001). Successful algal biodiesel production mainly depends on choosing the good species with relevant biomass and lipid productivity. The freshwater chlorophytes Scenedesmus obliquus and Micractinium reisseri can grow in wastewaters of different origins showing good adaptation ability (Hodaifa et al., 2008; 2009). In addition, they are of the best candidates for biodiesel production among several microalgae species because of their high biomass production (Gouveia and Oliveira, 2009; Ruiz et al., 2013). Abomohra et al. (2013) screened 13 freshwater microalgae as a feedstock for biodiesel. They concluded that Scenedesmus obliquus was selected as a promising microalga for large-scale lipid production because of its high biomass production which resulted in high lipid and fatty acid productivities. In addition, Eldalatony (2013) screened the efficiency of wastewater isolated microalgae for biodiesel production and nominated Micractinium reisseri as the promising species. The present work was intended to compare the growth of both microalgae on different growth media in order to select the suitable medium and harvest time for each species.

\section{Material and Methods:}

\section{Algal strains and growth media:}

Scenedesmus obliquus (SAG276-10) was obtained from Culture Collection of Algae at Gottingen University, Germany. Micractinium reisseri (JN169781) isolated from agriculture drainage mixed with municipal wastewater at El-Gharbya Governorate, Egypt (AbouShanab et al., 2014). Four different photoautotrophic media were tested, namely $\mathrm{KC}$ (Kessler and Czygan, 1970), Kuhl (Kuhl and Lorenzen, 1964), Chu-10 (Stein, 1973) and $2 \mathrm{~g} \mathrm{~L}^{-1}$ Flory Basis Fertilizer 1 (Euflor, Germany) and $810 \mathrm{mg} \mathrm{L}^{-1} \mathrm{KNO}_{3}$; $\mathrm{pH}$ : 7.0 (Table 1).

Table 1. Composition of different media used for the cultivation of Scenedesmus obliquus and Micractinium reisseri.

\begin{tabular}{|c|c|c|c|c|}
\hline \multirow{2}{*}{$\begin{array}{l}\text { Chemical } \\
\text { compounds }\end{array}$} & \multicolumn{4}{|c|}{ Concentration $\left(\mathrm{mg} \mathrm{L}^{-1}\right)$} \\
\hline & $\mathrm{KC}$ & Kuhl & Chu-10 & Flory \\
\hline $\mathrm{KNO}_{3}$ & 810 & 1011.1 & - & - \\
\hline $\mathrm{NaCl}$ & 470 & - & - & - \\
\hline $\mathrm{NaH}_{2} \mathrm{PO}_{4} \cdot \mathrm{H}_{2} \mathrm{O}$ & 470 & 621 & - & - \\
\hline $\mathrm{Na}_{2} \mathrm{HPO}_{4} \cdot 2 \mathrm{H}_{2} \mathrm{O}$ & 360 & 89 & - & - \\
\hline $\mathrm{MgSO}_{4} .7 \mathrm{H}_{2} \mathrm{O}$ & 250 & 246.5 & 25 & - \\
\hline$\left(\mathrm{NH}_{4}\right)_{6} \mathrm{Mo}_{7} \mathrm{O}_{24} \cdot 4 \mathrm{H}_{2} \mathrm{O}$ & 0.2 & 0.0125 & - & - \\
\hline $\mathrm{CaCl}_{2} \cdot 2 \mathrm{H}_{2} \mathrm{O}$ & 15 & 14.7 & - & - \\
\hline $\mathrm{ZnSO}_{4} .7 \mathrm{H}_{2} \mathrm{O}$ & 0.2 & 0.287 & 0.222 & - \\
\hline $\mathrm{H}_{3} \mathrm{BO}_{3}$ & 0.5 & 0.061 & 2.86 & - \\
\hline $\mathrm{MnCl}_{2} .4 \mathrm{H}_{2} \mathrm{O}$ & 0.5 & - & 1.81 & - \\
\hline $\mathrm{NH}_{4} \mathrm{NO}_{3}$ & - & - & - & 810 \\
\hline EDTA & 8 & - & - & - \\
\hline $\mathrm{Na}-\mathrm{EDTA}$ & - & - & 1 & - \\
\hline $\mathrm{NaMoO}_{4} .5 \mathrm{H}_{2} \mathrm{O}$ & - & - & 0.390 & - \\
\hline $\mathrm{MnSO}_{4} \cdot \mathrm{H}_{2} \mathrm{O}$ & - & 0.169 & - & - \\
\hline $\mathrm{CuSO}_{4} .5 \mathrm{H}_{2} \mathrm{O}$ & - & 0.0025 & 0.079 & - \\
\hline $\mathrm{Na}_{2} \mathrm{SiO}_{3} .9 \mathrm{H}_{2} \mathrm{O}$ & - & - & 58 & - \\
\hline $\mathrm{Ca}(\mathrm{NO} 3)_{2} \cdot 4 \mathrm{H}_{2} \mathrm{O}$ & - & - & 57.5 & - \\
\hline $\mathrm{Na}_{2} \mathrm{CO}_{3}$ & - & - & 20 & \\
\hline $\mathrm{K}_{2} \mathrm{HPO}_{4}$ & - & - & 10 & - \\
\hline $\mathrm{Co}(\mathrm{NO} 3)_{2} \cdot 6 \mathrm{H}_{2} \mathrm{O}$ & - & - & 0.049 & - \\
\hline \multicolumn{5}{|l|}{ Fe-EDTA complex } \\
\hline $\mathrm{FeSO}_{4} \cdot 7 \mathrm{H}_{2} \mathrm{O}$ & 6 & 6.95 & 4 & - \\
\hline $\mathrm{Na}_{2}$-EDTA & - & 9.3 & 4.16 & - \\
\hline $\mathrm{KHCO}_{3}$ & - & - & 4.32 & - \\
\hline N-free Flory Basic & - & - & - & 2000 \\
\hline
\end{tabular}


Fertilizer 1

\section{Microalgae growth conditions:}

The initial axenically cultivation of the two microalgal strains was obtained in $250 \mathrm{ml}$ Erlenmeyer flasks containing $100 \mathrm{ml}$ of $\mathrm{KC}$ medium. The cultures were incubated at $25 \pm 1{ }^{\circ} \mathrm{C}$ under continuous illumination using tubular fluorescent lamps (FL 40 T9D/38) with a light intensity of 3000 lux at the surface of the culturing vessels. A 2-weeks old culture, at vegetative cell growth phase, was used as inoculum for all experiments. For selection of the suitable medium providing best growth under photoautotrophic conditions, S. obliquus and $M$. reisseri were individually cultivated in the four media. All cultures were grown under sterilized conditions in $1000 \mathrm{ml}$ Erlenmeyer flasks, each containing $700 \mathrm{ml}$ of the growth medium, at an initial optical density $\left(\mathrm{OD}_{680}\right)$ of 0.01 . The cultures were incubated at $25 \pm 1{ }^{\circ} \mathrm{C}$ under continuous light intensity of 3000 lux. To avoid settling, and for accelerating the growth process, continuous aeration was supplied to the culture to provide necessary $\mathrm{CO}_{2}$ at a flow rate of $1 \mathrm{~L} \mathrm{~min}^{-1}$ by bubbling of filtersterilized air

\section{Biomass assay:}

Growth curves and biomass concentrations were evaluated by measuring the optical density at $680 \mathrm{~nm}$ $\left(\mathrm{OD}_{680}\right)$ and algal cellular dry weight $\left(\mathrm{CDW}, \mathrm{g} \mathrm{L}^{-1}\right)$. Dry weight was estimated by centrifugation of $40 \mathrm{ml}$ of the culture at $2000 \mathrm{~g}$ for $10 \mathrm{~min}$, then cell pellets were washed twice using distilled water, and then oven dried at $80^{\circ} \mathrm{C}$ until constant weight.

\section{Estimation of total lipids:}

Extraction of lipids was done using chloroform: methanol $(2: 1)$ according to the method described by Folch et al. (1957). The pre-weighted glass vials containing the lipid extracts were dried at $80{ }^{\circ} \mathrm{C}$ for 30 min, cooled in a desiccator and weighed.

\section{Productivity Calculation:}

Biomass and lipid productivities were calculated according to (Andrade and Costa, 2007) and modified by Abomohra et al. (2013)

Biomass productivity $\left(\mathrm{g} \mathrm{L}^{-1} \mathrm{~d}^{-1}\right)=\left(\mathrm{CDW}_{\mathrm{L}}-\mathrm{CDW}_{0}\right) \cdot\left(\mathrm{T}_{\mathrm{L}^{-}}\right.$

$$
\left.\mathrm{T}_{0}\right)^{-1}
$$

Where $\mathrm{CDW}_{0}$ and $\mathrm{CDW}_{\mathrm{L}}$ representing the $\mathrm{CDW}\left(\mathrm{g} \mathrm{L}^{-1}\right)$ at the starting cultivation day $\left(\mathrm{T}_{0}\right)$ and days of late exponential phase $\left(T_{L}\right)$, respectively.

Lipid productivity $\left(\mathrm{mg} \mathrm{L}^{-1} \mathrm{~d}^{-1}\right)=\left(\mathrm{L}_{\mathrm{D}}-\mathrm{L}_{0}\right)$. $\left(\mathrm{T}_{\mathrm{D}}-\mathrm{T}_{0}\right)^{-1}$
Where $\mathrm{L}_{0}$ and $\mathrm{L}_{\mathrm{D}}$ representing the total lipid $\left(\mathrm{mg} \mathrm{L}^{-1}\right)$ at the starting cultivation day $\left(\mathrm{T}_{0}\right)$ and days of the desired phase $\left(T_{D}\right)$, respectively.

\section{Fatty acid profiles:}

The extracted lipids were saponified overnight with ethanolic $\mathrm{KOH}(20 \%, w / v)$ at room temperature. Fatty acids were librated from their potassium salts by acidification with $5 \mathrm{~N}$ Hydrochloric acid followed by extraction using petroleum ether at $40-60{ }^{\circ} \mathrm{C}$. The ether extract containing fatty acid methyl esters was washed three times with distilled water and dried over anhydrous sodium sulfate (Vogel 1975). Fatty acid profile was analyzed using GC-MS (Hewlett Packard HB 5890, coupled with 5989 B series mass spectrometer). The initial temperature was $70{ }^{\circ} \mathrm{C}$ and gradually accelerated to $250{ }^{\circ} \mathrm{C}$ at a rate of $10{ }^{\circ} \mathrm{C}$ per minute. The maximum peaks representing mass to charge ratio characteristics of fatty acids were compared with those in the mass spectrum library (Pandey et al., 2010). The proportion of each fatty acid (\%) was calculated by the following formula,

$$
\text { Fatt acid proportion }=\frac{F}{F_{t}} \times 100
$$

Where, $F$ is the peak area of the desired fatty acid and $F_{t}$ is the total peak area for the fatty acid methyl ester.

\section{Statistical Analysis:}

Results are presented as the mean of three replicates \pm standard deviation (SD). The statistical analyses were carried out using SAS (v 6.12). Data obtained were analyzed statistically to determine the degree of significance using one way analysis of variance (ANOVA) at $\mathrm{p} \leq 0.05$.

\section{Results:}

Among the four tested media, Kuhl and $\mathrm{KC}$ media showed the highest growth for $S$. obliquus and $M$. reisseri, respectively (Figure 1). The duration of the exponential phase of $S$. obliquus on the four tested growth media varied between 6 to 20 days, while the exponential phase duration for M. reisseri varied between 14 to 22 days (Table 2). The results showed the highest biomass productivity for M. reisseri on KC medium $\left(0.07 \mathrm{~g} \mathrm{~L}^{-1} \mathrm{~d}^{-}\right.$ ${ }^{1}$ ) which was $40.8 \%$ higher than that of $S$. obliquus on Kuhl medium. Accordingly, Lipid productivity and fatty acid profile of $S$. obliquus and $M$. reisseri were studied using the corresponding optimal medium for each strain. 

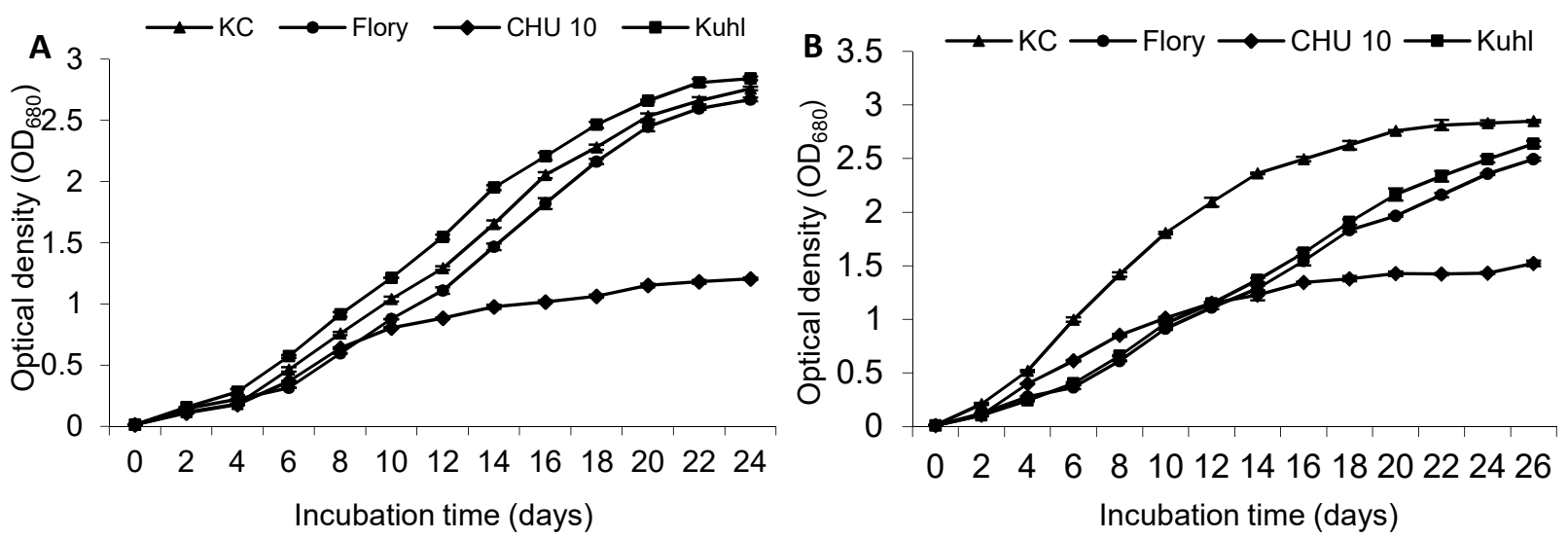

Figure 1. Growth curves of S. obliquus (A) and M. reisseri (B) cultivated on the four different growth media.

Table 2. Comparison of growth parameters of $S$. obliquus and $M$. reisseri grown in different culture media.

\begin{tabular}{llccc}
\hline Microalgae & Growth media & $\begin{array}{c}\text { Duration of } \\
\text { exponential phase }\end{array}$ & $\begin{array}{c}\text { CDW }\left(\mathrm{g} \mathrm{L}^{-1}\right) \\
\text { at late exponential phase }\end{array}$ & $\begin{array}{c}\text { Biomass productivity } \\
\left(\mathrm{g} \mathrm{CDW} \mathrm{L}^{-1} \mathrm{~d}^{-1}\right)\end{array}$ \\
\hline \multirow{3}{*}{ S. obliquus } & KC & 20 & $1.00 \pm 0.033^{\mathrm{a}}$ & $0.04 \pm 0.003^{\mathrm{ab}}$ \\
& Flory & 16 & $0.93 \pm 0.033^{\mathrm{a}}$ & $0.04 \pm 0.001^{\mathrm{a}}$ \\
& CHU- 10 & 6 & $0.50 \pm 0.033^{\mathrm{b}}$ & $0.02 \pm 0.002^{\mathrm{c}}$ \\
& Kuhl & 18 & $1.20 \pm 0.030^{\mathrm{ce}}$ & $0.05 \pm 0.002^{\mathrm{bd}}$ \\
\hline \multirow{3}{*}{ M. reisseri } & KC & 18 & $1.38 \pm 0.080^{\mathrm{d}}$ & $0.07 \pm 0.004^{\mathrm{e}}$ \\
& Flory & 22 & $1.18 \pm 0.029^{\mathrm{cf}}$ & $0.05 \pm 0.004^{\mathrm{d}}$ \\
& CHU- 10 & 14 & $1.10 \pm 0.090^{\mathrm{f}}$ & $0.03 \pm 0.002^{\mathrm{c}}$ \\
& Kuhl & 22 & $1.28 \pm 0.080^{\mathrm{e}}$ & $0.06 \pm 0.006^{\mathrm{f}}$
\end{tabular}

Each value is the mean of three readings \pm standard deviation. Mean value in the same column with different letters in the superscript are significantly different $(\mathrm{p}<0.05)$

Figure 2 shows lipid content and lipid productivity of $S$. obliquus grown in Kuhl medium at different growth phases. There was a statistically significant increase (of $86.25 \%$ ) in the lipid content of S. obliquus from early exponential phase to stationary phase, while the increase in lipid content showed insignificant difference between late exponential phase and stationary phase. Lipid productivity of $S$. obliquus at stationary phase was 12.61 $m g L^{-1} \mathrm{~d}^{-1}$ which was insignificant with that at the late exponential phase $\left(12.55 \mathrm{mg} \mathrm{L}^{-1} \mathrm{~d}^{-1}\right)$. Lipid content of $M$. reisseri showed the same pattern as $S$. obliquus (Figure $3)$. It was increased by $55.61 \%$ from early exponential to stationary phase, while the increase was insignificant from late exponential to stationary phase. However, $M$. reisseri showed higher lipid productivity at stationary phase (17.08 $\left.\mathrm{mg} \mathrm{L}^{-1} \mathrm{~d}^{-1}\right)$ which was $35.45 \%$ higher than that of $S$. obliquus. In addition, lipid productivity of $M$. reisseri at stationary phase was significantly higher than that at other growth phases.

The fatty acid composition of S. obliquus and M. reisseri grown on the two best media (Kuhl and KC, respictively) were studied at stationary growth phase and represented in Table 3. The result showed that the two studied species are characterized by high percentage of saturated fatty acid 81.34 and $72.51 \%$ for $S$. obliquus and M. reisseri, respectively. The highest percentage of SFA in $S$. 
obliquus grown on Kuhl medium was due to the presence of Tridecylic (C13:0), Palmitic (C16:0), Stearic (C18:0), Lauric (C12:0) which represented by $19.53 \%, 15.74 \%$, $10.05 \%$ and $7.34 \%$ of the total fatty acids, respectively. On the other hand, the highest content of monounsaturated fatty acids (MUFAS) constituted 27.49 $\%$ was recorded in $M$. reisseri which due to the presence of Myristoleic (C14:1) and Pentadecenoic acid (C15:1). Finally, the total polyunsaturated fatty acids (PUFAs) constituted $2.93 \%$ of the total fatty acids in S. obliquus due to the presence of Linoleic (C18:2c). (Table3).

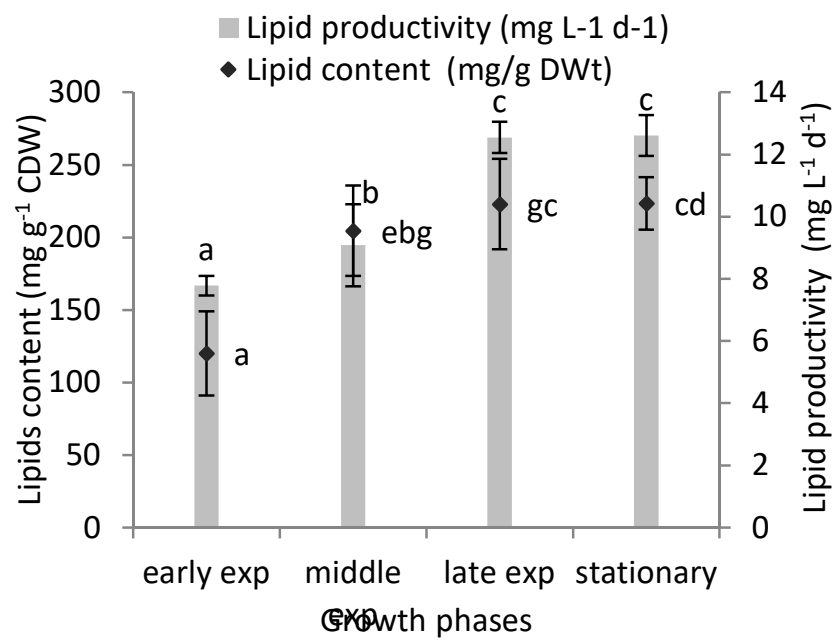

Figure 2. Variation of lipid content and lipid productivity of S. obliquus cultivated in kuhl medium at different growth phases. Error bars show the SD for three measurements; the significance of differences is denoted by different letters $(\mathbf{p}<\mathbf{0 . 0 5})$

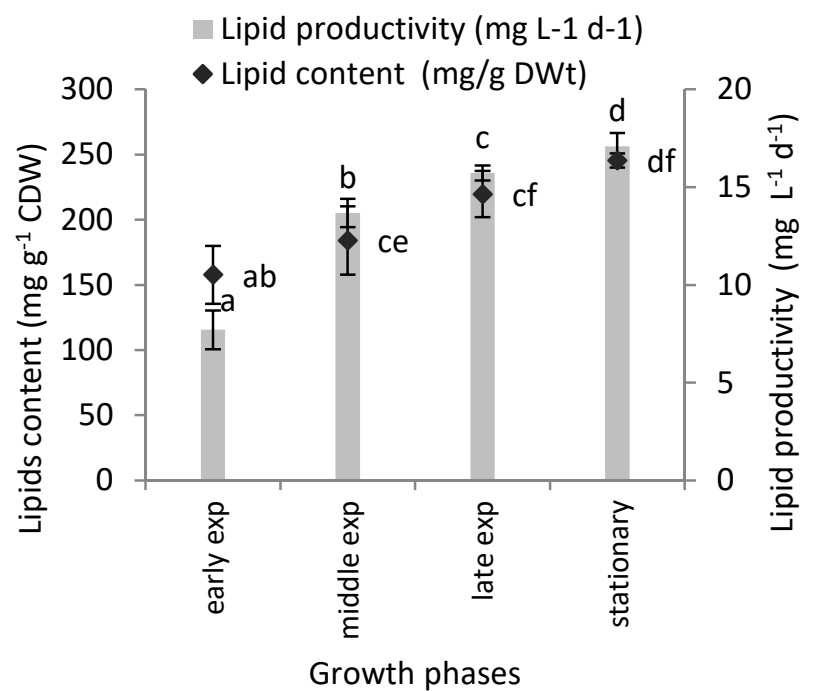

Figure 3. Variation of lipid content and lipid productivity of $M$. reisseri cultivated in $\mathrm{KC}$ medium at different growth phases. Error bars show the SD for three measurements; the significance of differences is denoted by different letters $(\mathbf{p}<\mathbf{0 . 0 5})$.
Table 3. Fatty acid profiles of $S$. obliquus and $M$. reisseri measured at stationary growth phase. Values are given as percent (\%) of total fatty acids. SFA Saturated fatty acid, UFA unsaturated fatty acid

\begin{tabular}{lcc}
\hline \multicolumn{1}{c}{ Fatty acids } & S. obliquus & M. reisseri \\
\hline SFAs & $n d$ & 0.47 \\
Caprylic (C8:0) & 1.82 & 0.70 \\
Capric(C10:0) & 3.62 & $n d$ \\
Undecylic(C11:0) & 7.34 & 5.20 \\
Lauric(C12:0) & 19.53 & 12.03 \\
Tridecylic(C13:0) & 13.87 & 20.28 \\
Myristic(C14:0) & 9.37 & 16.68 \\
Pentadecylic(C15:0) & 15.74 & 16.06 \\
Palmitic(C16:0) & 10.05 & 1.09 \\
Stearic(C18:0) & 81.34 & 72.51 \\
Sum SFAs & & \\
& & \\
MUFAs & 7.79 & 12.51 \\
Myristoleic(C14:1) & $n d$ & 14.98 \\
Pentadecenoic acid (C15:1) & 7.94 & $n d$ \\
Oleic(C18:1c) & 15.73 & 27.49 \\
Sum NUFAs & & \\
& & \\
PUFAs & 2.93 & $n d$ \\
Linoleic(C18:2c) & 2.93 & \\
Sum PUFAs & & \\
\hline nd means not detected & & \\
& &
\end{tabular}

nd means not detected

\section{Discussion:}

The present study mainly focused on freshwater microalgae which can be found in the local freshwater ponds and also be able to grow easily under laboratory conditions. S. obliquus and $M$. reisseri were selected as good strains for this work based on literature review (Abomohra et al., 2013; Eldalatony, 2013; Abou-Shanab et al., 2014; Onay et al., 2014). The selection of these strains was based on high growth rate and/or high lipid content which results in high lipid productivity. The selection of the suitable medium for high biomass and lipid production depends on the growth requirements of the algae, how the constituents of the medium may affect 
final product quality and the components cost (Borowitzka, 2005).

The highest biomass productivity for $M$. reisseri was recorded on $\mathrm{KC}$ medium which was $25 \%$ higher than that recorded by Abou-Shanab et al. (2014) for M. reisseri grown on bold basal medium for 20 days. The higher biomass productivity for $M$. reisseri grown in $\mathrm{KC}$ medium is correlated to its chemical composition, which containing all growth requirements for $M$. reisseri such as higher concentration of $\mathrm{Na}_{2} \mathrm{HPO}_{4} \cdot 2 \mathrm{H}_{2} \mathrm{O}, \mathrm{MgSO}_{4} .7 \mathrm{H}_{2} \mathrm{O}$ and $\left(\mathrm{NH}_{4}\right)_{6} \mathrm{Mo}_{7} \mathrm{O}_{24} .4 \mathrm{H}_{2} \mathrm{O}$ as a source of phosphorus, $\mathrm{Mg}^{2+}$ and $\mathrm{Mo}^{2+}$, respectively, compared to other media. In addition, the presence of $\mathrm{NaCl}$ in $\mathrm{KC}$ medium may change the salinity of water that affects the growth, metabolism and photosynthesis of microalgae (Moisander et al., 2002; Lartigue et al., 2003).

The higher biomass productivity of $S$. obliquus grown in Kuhl medium might be related to higher concentration of $\mathrm{KNO}_{3}, \mathrm{FeSO}_{4} .7 \mathrm{H}_{2} \mathrm{O}$ and $\mathrm{ZnSO}_{4}$ as a source of nitrogen, iron and $\mathrm{Zn}^{2+}$, respectively, compared to other tested media, which are an essential constituents of all structural and functional components of the algal cells (Terry and Abadía, 1986; Chu et al., 2007). In addition, the presence of $\left(\mathrm{CuSO}_{4} .5 \mathrm{H}_{2} \mathrm{O}\right)$ as a source of cupper in low concentration compared to its high concentration in Chu-10 medium or its absence in KC medium. Cupper is one of the essential micronutrients that required for microalgal growth and involved in numerous metabolic processes, including photosynthesis and energy storage (Liu et al., 2008; Chen et al., 2011).

Growth phase of the culture also affects lipid content and fatty acid composition. In many algal species the increase in lipid content is often observed during stationary phase. Therefore, the highest lipid content of $S$. obliquus and $M$. reisseri in stationary phase cultures might be due to the shift in lipid metabolism from membrane lipid synthesis to the storage of neutral lipids. That shift in lipid metabolism because of the depletion of essential nutrients, including nitrogenous compounds that are necessary for protein synthesis, and phosphatecontaining compounds which are needed for the formation of phospholipids that are major structural components of cell-membranes (Dunstan et al., 1993; Brown et al., 1996). In accordance to the present results, Bigogno et al. (2002) found that total fatty acid portion forming triacylglycerols (TAGs) in the chlorophyte Parietochloris incise increased from $43 \%$ in the logarithmic phase to $77 \%$ in the stationary phase.

The continuous increase in the lipid content of $S$. obliquus and $M$. reisseri from early exponential phase to stationary phase, in addition to the increase of biomass productivity resulted in increase in lipid productivity for both strains from early exponential phase to stationary phase. Lipid productivity of $M$. reisseri showed significant differences a long side different growth phases. However, the increase in lipid productivity of $S$. obliquus from late exponential phase to stationary phase showed insignificant difference which suggests the optimum harvest times for M. reisseri and S. obliquus at stationary phase and late exponential phase, respectively. The obtained results showed increase in lipid productivity of $M$. reisseri due to its higher biomass productivity which makes this microorganism desirable for further studies on optimization of lipid production and on largescale cultivation.

Saturated fatty acid contents and chain length of algae lipids would cause noticeable changes in the biodiesel properties. Saturated fatty acids have significantly higher melting points than unsaturated fatty acids. Therefore, biodiesel fuels derived from fats or oils with significant amounts of saturated fatty compounds display poor cold flow properties (Dunn, 2005). In accordance to the present results, Knothe (2009) reported that the most common fatty acids methyl esters (FAMEs) present in biodiesel with good burning qualities are palmitic acid (C16:0) and oleic acid (C18:1n9c), which were also the major fatty acids in both studied miceoalgae in the present study.. The high percentage of saturated fatty acids, e.g. palmitic acid (C16:0), increases the biodiesel quality due to increasing of cetane number which decreased by increasing the degree of unsaturation (Kinoshita et al., 2006).

On the other hand, Zhang et al. (2008) concluded that higher content of polyunsaturated fatty acid in the feedstock oil causes deterioration in the quality of biodiesel upon storage, due to oxidation, or even the structural features of the fatty acids. Although the fatty acid profile of both studied microalgae showed superior characteristics to be used as feedstock for biodiesel production, the higher lipid productivity of $M$. reisseri makes it one of the best candidates for biodiesel synthesis.

In conclusion, the effect of different culture media on the growth and lipid productivity of green microalgal strains $S$. obliquus and $M$. reisseri suggested M. reisseri grown in $\mathrm{KC}$ medium is the most suitable microalga for biodiesel production because it showed higher biomass and lipid productivities.

\section{References}

Abomohra A, Wagner M, El-Sheekh M, Hanelt D. (2013): Lipid and total fatty acid productivity in photoautotrophic fresh water microalgae: screening studies towards biodiesel production. Journal of Applied Phycology 25:931- 936. 
Abou-Shanab R, El-Dalatony M, EL-Sheekh M, Ji M, Salama E, Kabra A, Jeon B. (2014): Cultivation of a New Microalga, Micractinium reisseri, in Municipal Wastewater for Nutrient Removal, Biomass, Lipid, and Fatty Acid Production. Biotechnology and Bioprocess Engineering 19:510-518.

Andrade MR, Costa JAV.(2007) :Mixotrophic cultivation of microalga Spirulina platensis using molasses as organic substrate, Aquaculture 264: 130134.

Barnwal BK, Sharma MP. (2005): Prospects of biodiesel production from vegetables oils in India. Renewable \& Sustainable Energy Reviews 9:363-378.

Batten D, O'Connell D. (2007): Biofuels in AustraliaSome Economic and Policy Issues, Rural Industries Research and Development Corporation. Canberra, Australia

Bigogno C, Khozin-Goldberg I, Boussiba S, Vonshak A, Cohen Z. (2002): Lipid and fatty acid composition of the green oleaginous alga Parietochloris incisa, the richest plant source of arachidonic acid. Phytochemistry 60:497-503.

Borowitzka MA. (2005): Culturing microalgae in outdoor ponds. In: Algal culturing techniques (ed. Anderson RA), 1st edn. pp 205-219. Elsevier, Burlington, USA.

Brown MR, Dunstan GA, Norwood SJ, Miller KA. (1996): Effects of harvest stage and light on the biochemical composition of the diatom Thalassiosira pseudonana. Journal of applied Phycology 34: 64-73.

Campbell PK, Beer T, Batten D. (2011): Life cycle assessment of biodiesel production from microalgae in ponds. Bioresource Technology 102(1):50-56.

Chen M, Tang H, Ma H, Holland TC, Ng KS, Salley SO. (2011): Effect of nutrients on growth and lipid accumulation in the green algae Dunaliella tertiolecta. Bioresource Technology 102:1649-1655.

Chisti Y. (2007): Biodiesel from microalgae. Biotechnology Advances 25:294-306.

Chu ZS, Jin XC, Yan F, Zheng SF, Pang Y, Zeng QR. (2007): Effects of EDTA and iron on growth and competition of Microcystis aeruginosa and Scenedesmus quadricauda. Huanjing Kexue/Environmental Science 28(11): 2457- 2461.

Dunn RO. (2005): Cold weather properties and performance of biodiesel. in The Biodiesel Handbook, edited by Kanthe G, van Gerpen J, and Krahl J (AOCS Press, Champaign, IL, USA).

Dunstan GA, Volkman JK, Barrett SM, Garland CD. (1993): Changes in the lipid composition and maximization of the polyunsaturated fatty acid content of three microalgae grown in mass culture. Journal of Applied Phycology 5: 71-83.

Eldalatony MA. (2013): Molecular and physiological studies of algae grown on wastewater as valuable candidate production. MSc thesis, Tanta University, Egypt.

Folch J, Lees M, Stanley GHS. (1957): A simple method for the isolation and purification of total lipids from animal tissues. Journal of Biological Chemistry 226:497-509.

Fukuda H, Kondo A, Noda H. (2001): Biodiesel fuel production by transesterification of oils. Journal of Bioscience and Bioengineering 92:405-1.

Gouveia L, Oliveira AC. (2009): Microalgae as a raw material for biofuels production. Journal of Industrial Microbiology and Biotechnology 36: 269-274.

Hodaifa G, Martínez ME, Sánchez S. (2008): Use of industrial wastewater from olive-oil extraction for biomass production of Scenedesmus obliquus. Bioresource Technology 99: 1111-1117.

Hodaifa G, Martínez ME, Sánchez S. (2009): daily doses of light in relation to the growth of Scenedesmus obliquus in diluted three-phase olive mill wastewater. Journal of Chemical Technology and Biotechnology 84: 1550-1558.

Kessler E, Czygan FC. (1970): Physiologische und biochemischen Beitra"ge zur Taxonomie der Gattung Chlorella. Archiv fur Mikrobiologie 70:211-216.

Kinoshita E, Myo T, and Hamasaki K,. (2006): Diesel combustion characteristics of coconut oil and palm oil biodiesels. Society of Automotive Engineers, Technical paper series, $01-3251$, Power Train and Fluid Systems Conference and Exhibition, Toronto, Canada, October $16-19$.

Knothe G. (2009): Improving biodiesel fuel properties by modifying fatty ester composition. Energy and Environmental Science 2: 759-766.

Kuhl A, Lorenzen H. (1964): Handling and culturing of Chlorella. In: D. M. Prescott, ed., Methods in cell physiology I:152-187, Academic press, New York and London.

Lartigue J, Neill A, Hayden BL, Pulfer J, Cebrian J. (2003): The impact of salinity fluctuations on net oxygen production and inorganic nitrogen uptake by Ulva lactuca (Chlorophyceae). Aquatic Botany 75: 339- 350.

Liu ZY, Wang GC, Zhou BC. (2008): Effect of iron on growth and lipid accumulation in Chlorella vulgaris. Bioresource Technology 99:4717-4722.

Lo YC, Chen CY, Lee CM, Chang JS. (2010): Sequential dark-photo fermentation and autotrophic microalgal growth for high-yield and $\mathrm{CO} 2$-free biohydrogen production.International Journal of Hydrogen Energy 35: 10944-10953.

Mata TM, Martins AA, Caetano NS. (2010): Microalgae for biodiesel production and other applications: a review. Renewable and Sustainable Energy Reviews 14: 217-232.

Effect of different culture media on the growth and lipids of the green microalgae, Scenedesmus obliquus and Micractinium reisseri as a feedstock for biodiesel production 
Moisander PH, McClinton E, Paer HW. (2002): Salinity effects on growth, photosynthetic parameters, and nitrogenase activity in estuarine planktonic cyanobacteria. Microbial Ecology 43: 432- 442.

Onay M, Sonmez C, Oktem HA, Yucel AM. (2014): Thermo-resistant green microalgae for effective biodiesel production: Isolation and characterization of unialgal species from geothermal flora of Central Anatolia. Bioresource Technology 169: 62-71.

Pandey A, Milind M, Naik DK. (2010): Organic metabolites produced by Vibrio parahaemolyticus strain An3 isolated from Goan mullet inhibit bacterial fish pathogens Goa, India. African Journal of Biotechnology 9(42): 7134-7140.

Ruiz J, Álvarez-Díaz PD, Arbib Z, Garrido-Pérez C, Barragán J, Perales JA. (2013): Performance of a flat panel reactor in the continuous culture of microalgae in urban wastewater: Prediction from a batch experiment. Bioresource Technology 127:456-463.
Singh J, Gu S. (2010): Commercialization potential of microalgae for biofuels production. Renewable and Sustainable Energy Reviews 14:2596-2610.

Stein J. (1973): Handbook of phycological methods: culture methods and growth measurements. Cambridge University Press, Cambridge.

Stephens E, Ross IL, King Z, Mussgnug JH, Kruse O, Posten C, Borowitzka M, Hankamer B. (2010): An economic and technical evaluation of microalgal biofuels. Nature Biotechnol 28:126-128.

Terry N, Abadía J. (1986): Function of iron in chloroplasts. Journal of Plant Nutrition 9: 609-646.

Vogel AI. (1975): Atext book of practical organic chemistry, 3rdedn. Longman, London

Zhang ED, Wang B, Wang QH, Zhang SB, Zhao BD. (2008): Ammonia-nitrogen and orthophosphate removal by immobilized Scenedesmus $s p$. isolated from municipal wastewater for potential use in tertiary treatment. Bioresource Technology 99: 37873793.

\section{تأثير أنواع مختلفة من الأوساط الغذائية على نمو الطحالب الخضراء سينيدزمس اوبليكس وميكر اكتينيوم ريزيرا كمصدر لانتاج الديزل الحيوى}

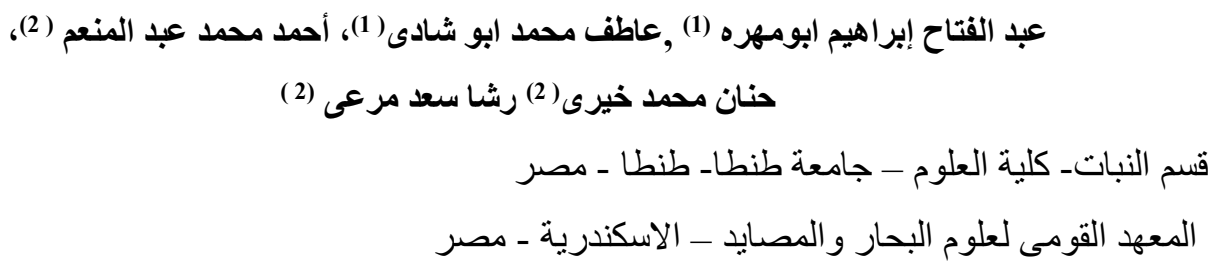

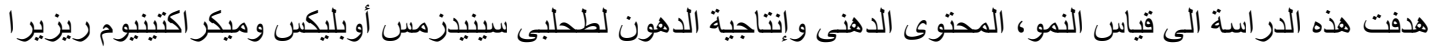
لاعتبار هما من الطحالب الدقيقة الو اعدة في إنتاج الديزل الحيوي والتئ تم تنميتهما على أوساط غذائية مختلفة. تم استخدام أربعة

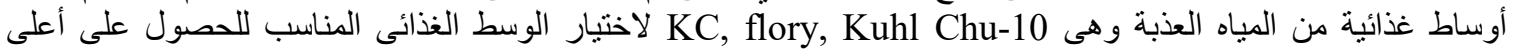

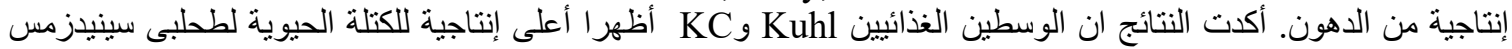

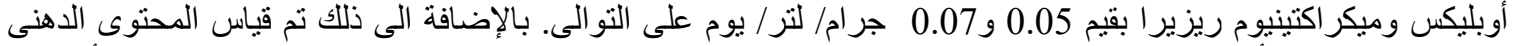

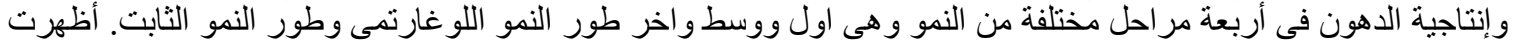

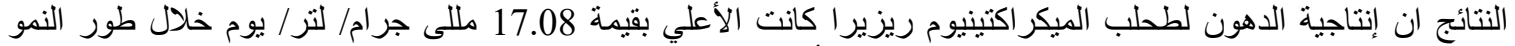

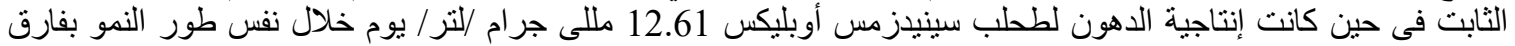

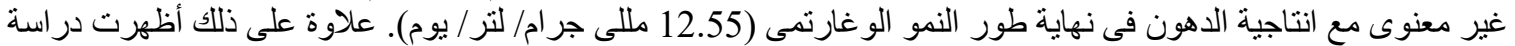

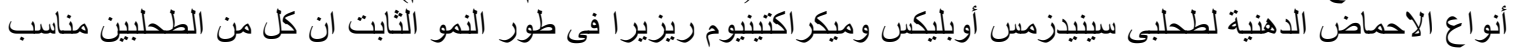

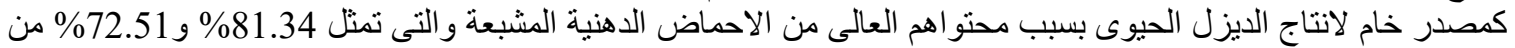

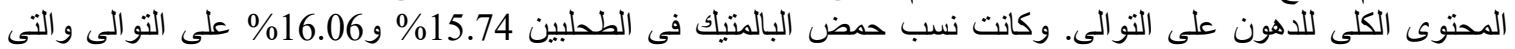

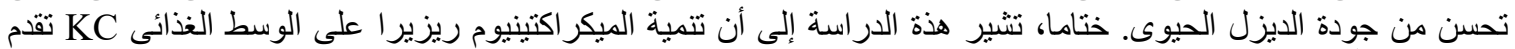

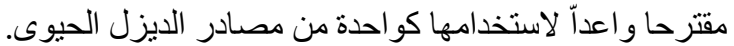

Effect of different culture media on the growth and lipids of the green microalgae, Scenedesmus obliquus and Micractinium reisseri as a feedstock for biodiesel production 